\title{
CHANGES WITHIN SMALL MAMMAL COMMUNITIES SINCE THE 1988 HUCKLEBERRY MOUNTAIN FIRE
}

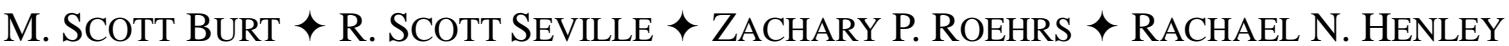 \\ DEPARTMENT OF ZOOLOGY AND PHYSIOLOGY $\downarrow$ UNIVERSITY OF WYOMING $\downarrow$ CASPER
}

\begin{abstract}
$\uparrow \quad$ ABSTRACT
This study is a continuation of investigations conducted at Huckleberry Mountain to determine the effect of the 1988 Greater Yellowstone fire on the small mammal community, and document changes in this community over the 22 years since this natural disturbance. Previous research was conducted in 1993, 1994, 1997, and 1998 and we sampled the same communities in 2009 and again in 2010 using the identical sampling methodology. During the summer of 2010 we live trapped 252 Southern Redbacked Vole (Myodes gapperi), 57 North American Deermouse (Peromyscus maniculatu), 22 Least Chipmunk (Tamias minimus), 12 Western Jumping Mouse (Zapus princeps), four Montane Vole (Microtus montanus), one Northern Pocket Gopher (Thomomys talpoides), four Cinereus Shrew (Sorex cinereus), and five Dusky Shrew (S. monticolus). These results are similar to our results from 2009 and corroborate findings from other investigations indicating early dominance of $P$. maniculatus in burned forests and M. gapperi in control unburned areas. M. gapperi and P. maniculatus accounted for the majority $(87 \%)$ of captures. In addition more $M$. gapperi were found in control sites than $P$. maniculatus, and as the burned habitat recovers over time, the relative numbers of $P$. maniculatus are decreasing, and the number of $M$. gapperi are increasing, suggesting that the burned habitats are returning to a more natural pre-disturbance community structure. However, community diversity indices (which include all mammal species and their relative proportions) suggest that there are still considerable differences between burned and unburned sites. Despite the numbers of voles and deermice changing over time (as predicted), the burned and control small mammal communities are still quite different from one another even after 22 years.
\end{abstract}

\section{$\downarrow \quad$ INTRODUCTION}

Biologists have long wondered about the role of disturbance in shaping communities, but few studies have looked at long-term responses following natural disturbances such as fire. Most studies have looked at shorter time frames (ten years or less), made comparisons among different sites, or investigated the role of manmade disturbances (e.g., prescribed burning). Few studies have specifically investigated short- and long-term changes in small mammal communities in response to natural forest fires, but patterns have emerged from previous research. An excellent review of this growing body of literature for boreal forests is provided by Fisher and Wilkinson (2005). In the early post fire stages (0-10 years), defined as the initiation stage (Lee, 2002), small mammal responses are variable and often include changes in relative abundance within the community rather than outright species replacements over time. Less is known regarding the intermediate, or establishment stage (Lee, 2002) 1125 years post fire in boreal forests. The same species are often present, but relative abundances differ from earlier stages.

The extensive 1988 fires of the Greater Yellowstone Area have provided biologists with an opportunity to study the short and longer term effects of a natural disturbance on small mammals and of the correlative or causative relationships between postfire successional stages of the vegetative community and small mammal community structure. Previous studies by Stanton et al. (1991, 1992, 1998) Spildie (1994), Seville et al. (1997) and Burt et al. (2009) at Huckleberry Mountain, Wyoming have investigated small mammal communities and habitat structure in both burned and unburned sites at 3, 4, 9, 10 and 21 years post-fire near Huckleberry Mountain in Grand Teton National Park. Taylor (1973) suggested that 
diversity is highest 25 years post-fire so the next few years are an opportune time to revisit the sites at Huckleberry Mountain and investigate the small mammal communities and the corresponding changes in habitat structure. Previous investigations occurred in 2 year, back-to-back seasons. To match previous effort and timing, we sampled the 4 trapping grids, 2 burned and two unburned, at similar times during the summers of 2009 and 2010.

Historically, the two species most commonly captured at the study sites have been the North American deermouse, Peromyscus maniculatus, and the southern red-backed vole, Myodes gapperi and these 2 species will be the focus for much of this investigation, though we will look at the entire small mammal community of each site. The generalist $P$. maniculatus typically responds positively in the years following fire and is often the most numerically dominant species. Data for $M$. gapperi are sometimes conflicting, though most studies suggest rapid re-colonization post-fire even though the species is believed to be an old-growth specialist. We were interested in investigating if this pattern of fire response for deermice and red-backed voles was similar at Huckleberry Mountain. Are deermice more abundant in the burn sites following the fires, and how do their numbers change over time? Are redbacked voles excluded from burned sites following fire, and if so, how long before their populations recover?

For the 2010 field season, we continued the series of investigations conducted at Huckleberry Mountain to continue to document changes in the small mammal communities since the 1988 fires. We used two measures to monitor changes among communities: diversity indices that incorporate species richness and evenness, and abundance and raw capture data for the two dominant species, $P$. maniculatus and $M$. gapperi. In addition we investigated changes in habitat structure of the study sites to assess associations or patterns between microhabitat variables and small mammal species. Our specific objectives were to:

1. Describe the diversity and composition of small mammal communities 22 years post-fire in burned and adjacent unburned study sites looking at both richness and evenness of species.

2. Compare the 2010 data with all previous years (where sufficient data are available), document changes in the communities, and determine if the communities are responding in predictable ways. At the beginning of the project we predicted that immediately after the 1988 fires, the burned sites would be substantially different (with lower diversity) than the control sites. Over the course of the investigations, small mammal diversity among control sites should remain fairly constant and the burned sites should show a gradual increase in diversity and more resemble the control sites. In addition, initially after the fires high numbers of Peromyscus maniculatus and few Myodes gapperi should be found in the burned sites, and as time progresses and the habitat recovers, the number of deermice should decrease as the number of redbacked voles increase.

3. Complete collection of habitat data and describe habitat structure, document habitat change over time, and analyze relationships between habitat structure and the presence of deermice and redbacked voles.

\section{$\uparrow \quad$ METHODS}

All trapping grids are located in Teton County Wyoming, Grand Teton National Park, 10.5 north of the junction with Leeks Marina road along highway 287. Specific UTM coordinates for each grid (all in zone 12) are: east facing burn (EFB) $0525026 \mathrm{E}, 4877860 \mathrm{~N}$; east facing control (EFC) 0524534E, 4877666N; west facing burn (WFB) 0525026E, 4877410N; west facing control (WFC) 0525020E, 4877386N. Trap effort (number of traps/grid, trap nights, and location) followed exactly the protocol from previous work at these locations. For one week during June, July, and August 2010 we sampled the identical burned (2) and unburned (2) 1 hectare trapping grids on Huckleberry Mountain studied by Stanton et al. (1991, 1992, 1998), Spildie (1994), Seville et al. (1997) and Burt et al. (2009). During each 4-day trapping period at each grid 100 Sherman traps were placed (100 stations/ha, $10 \mathrm{~m}$ apart) and baited with rolled oats and peanut butter. Traps were opened between 1530 and 1730 and checked between 0500 and 0830 the following day. Traps were closed for the duration of the day, and then reopened and re-baited (if necessary) the same afternoon. Compressed cotton squares were placed in each trap for insulation/nest construction. Pitfall traps were placed at every fourth trap station (25 pitfalls/grid) to capture insectivores. Captured animals were uniquely ear tagged and classified by species, sex, age class (juvenile or adult) and reproductive condition, weighed to the nearest gram and released where caught. Animals and traps were handled in accordance with current USFS employee guidelines for handling small rodents with the potential to transmit hantavirus. All field 
investigators wore HEPA half-mask respirators. At the end of each trapping session, all traps were cleaned with a $10 \%$ bleach solution.

Estimates of population abundance were calculated for $M$ gapperi and $P$. maniculatus for each grid within each trapping session using the program CAPTURE (White et al., 1978; Rexstad and Burnham, 1991). Abundance estimates were calculated for all populations among the four grids for each of the three months for 1997, 1998, 2009, and 2010. Capture data were not available for the 1990 and 1991 field seasons. The Removal model population estimation (with a variable probability removal estimator, M-bh) was selected with 4 occasions to represent 4 trapping nights for each session. We followed the recommendations of Pollock and Otto (1983) for the calculation of abundance estimates with removal data. Diversity within sites was estimated using the Shannon-Wiener Index $\left(\mathrm{H}^{\prime}=-\sum p_{i} \log p_{i}\right)$ and compared with indices from previous years.

In 2009, habitat data were collected from 80 randomly selected trap stations (20/grid). Data gathered at each trap station included distance from trap to nearest tree (within $5 \mathrm{~m}$ of trap station), diameter at breast height for tree, distance to nearest sapling (within $5 \mathrm{~m}$ of trap station), diameter at breast height for sapling, distance to nearest seedling (within $5 \mathrm{~m}$ ), and distance to nearest shrub (within $5 \mathrm{~m})$. A $5 \mathrm{~m}$ tape was laid down in the four cardinal directions (N, S, E, W), and at any point down woody debris (DWD; $>7.5 \mathrm{~cm}$ in diameter) crossed the tape, distance was measured from the trap station and the diameter of the woody debris and height above ground were recorded.

Cover class data gathered at each trap location included percent ground cover (in a 1 square meter area) for grass, herbs, leaf litter, bare ground, DWD, and logs. Cover class categories were scored $1-4$, with cover category 1 representing $0-25 \%$ ground cover, 2 representing $26-50 \%$ cover, 3 representing 51-75\% cover, and 4 representing 76$100 \%$ cover. The same 80 sites were resampled in 2010 for cover class. However, distances to nearest woody vegetation and DWD were not resampled for the 2010 season. We assumed negligible change in one year for these data. Since our data violated assumptions of standard t-tests and analysis of variance methods, nonparametric Mann-Whitney U tests were used to examine differences in vegetation parameters for the capture no-capture sites and Kruskal-Wallis tests were used for exploring vegetation differences between sites and possible relationships between species and vegetation. Since no differences were found in results from a standard ANOVA and the Kruskal-Wallis tests standard Tukey post-hoc tests were used to determine specific differences between factors in SPSS PASW Statistics 18.0.0 (IBM Corporation, Somers, NY).

\section{RESULTS}

\section{The 2010 season}

Eight species of mammals and 357 individuals were captured in 2010, including $252 \mathrm{M}$. gapperi, 57 P. maniculatus, 22 Tamias minimus, 12 Zapus princeps, four Sorex cinereus, five $S$. monticolus, four Microtus montanus, and one Thomomys talpoides. Total numbers of species by grid are provided in Table 1. Numbers are lower than 2009 primarily due to an abbreviated June trapping session due to grizzly bear activity. Therefore, reported values represent 4,000 trap nights instead of 4,800. As in previous years, $M$. gapperi and $P$. maniculatus accounted for the majority $(87 \%)$ of captures.

Table 1: Total number of each species captured per grid in 2010. EFB: east facing burn; EFC: east facing control; WFB: west facing burn; WFC: west facing control.

\begin{tabular}{|l|c|c|c|c|c|}
\hline & EFB & EFC & WFB & WFC & Total \\
\hline Myodes gapperi & 35 & 60 & 66 & 91 & 252 \\
\hline $\begin{array}{l}\text { Microtus } \\
\text { montanus }\end{array}$ & 1 & 0 & 1 & 2 & 4 \\
\hline $\begin{array}{l}\text { Peromyscus } \\
\text { maniculatus }\end{array}$ & 39 & 4 & 13 & 1 & 57 \\
\hline Sorex cinereus & 0 & 2 & 1 & 1 & 4 \\
\hline $\begin{array}{l}\text { Sorex } \\
\text { monticolus }\end{array}$ & 2 & 2 & 0 & 1 & 5 \\
\hline $\begin{array}{l}\text { Thomomys } \\
\text { talpoides }\end{array}$ & 0 & 0 & 1 & 0 & 1 \\
\hline Tamias minimus & 2 & 4 & 13 & 3 & 22 \\
\hline Zapus princeps & 1 & 1 & 1 & 9 & 12 \\
\hline & 80 & 73 & 96 & 108 & $\mathbf{3 5 7}$ \\
\hline
\end{tabular}

The east and west facing burned grids harbored more diverse small mammal communities than the east and west facing unburned control grids. Shannon-Wiener diversity indices for the 2010 season are as follows: east facing burn: 0.42283; east facing control: 0.309246; west facing burn: 0.408102; west facing control: 0.293397. The 2010 diversity indices were calculated with all species of shrews lumped together to accommodate comparison with previous years investigations in which shrew species data is not available. 
Estimates of population abundances were calculated for each grid in each month of trapping for the two most abundant species, M. gapperi and P.maniculatus, when sufficient data were available. Abundance estimates for M. gapperi (Figure 1) and $P$. maniculatus are presented in Figure 2 for years surveyed from 1997-2010. Red-backed voles have been detected in all grids since the studies began, and in general numbers have been higher in the control grids relative to the burned grids in 1988. However, numbers of voles are high in the west facing burn relative to the east facing burn, and in some years (2009, for example) numbers of voles are higher in the west facing burn than in the east facing control. Abundance of deer mice is clearly higher in the burned areas relative to the control sites. For every year of the study, the east facing burn supports a much higher number of deer mice than other sites.

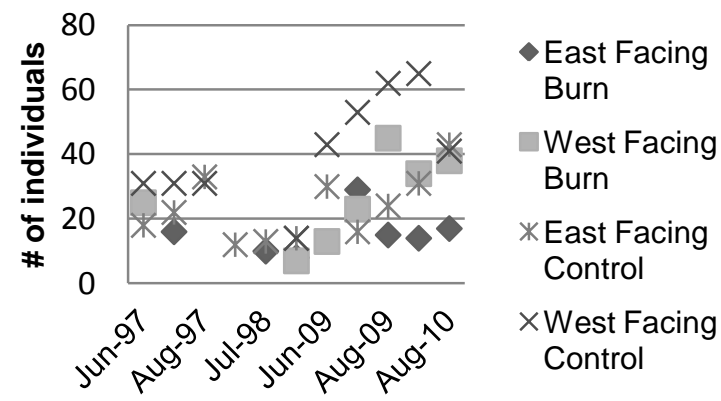

Figure 1. Abundance estimates for Myodes gapperi in the East Facing Burn (WFB), East Facing Control (EFC), West Facing Burn (WFB), and West Facing Control (WFC) grids from 1997-2010. Generally speaking, for each sampling period, there were more voles in control than burn sites. For the entire period, numbers were consistently low for the east facing burn, consistently high for the west facing control, and highly variable for the remaining two grids.

\section{Changes within communities since the fire}

Comparisons of proportions of small mammals by grids for the 1997, 1998, 2009 and 2010 seasons are presented in Figure 3-6. Myodes gapperi dominates the communities in both control grids. Peromyscus maniculatus dominates the community in the east facing burn, but not in the west facing burn relative to M. gapperi. Also, as time progresses, the number of rare species (e.g., Tamias minimus) has increased in the burned grids. No species capture data are available for 1993 and 1994, and a breakdown of shrew species is not available for the 1998 field season, so for all comparisons, shrews are lumped as Sorex spp.

As noted above, when looking at all 4 sites, generally more $M$. gapperi are found in control sites than $P$. maniculatus, and as the burned habitat recovers over time, the relative numbers of $P$. maniculatus are decreasing and the number of $M$. gapperi are increasing (Figures 7 and 8). However, community diversity indices (which include all mammal species and their relative proportions) suggest that there are still considerable differences between grids. Figure 9 illustrates changes in Shannon-Wiener diversity indices for the four grids for all studies since 1991. The communities from burned and unburned grids differed following the fires (greater diversity among the burned sites), and since that time, the differences between burned and unburned grids have generally remained, such that in 2010 the small mammal communities (as measured by diversity indices) are virtually identical to one another. Also note that for the first ten years, diversity in the burned areas increased, but in 2010 it appears that diversity in the burned grids is beginning to decrease. In contrast, after 22 years, diversity in the control sites is almost identical to the first years following the fires. These communities have changed little since that time.

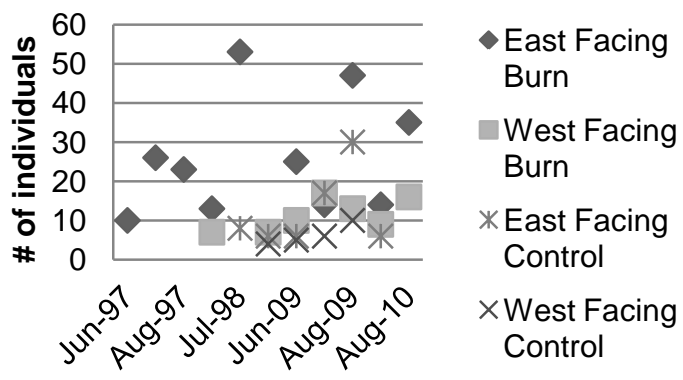

Figure 2. Abundance estimates for Peromyscus maniculatus in the four grids from 1997-2010. Generally speaking, for each sampling period, there were more deermice in burn than control grids. For the entire period, numbers were consistently low for both controls, and though numbers in burn sites were often higher than controls, numbers of deermice fluctuated greatly from year to year in the east facing burn.

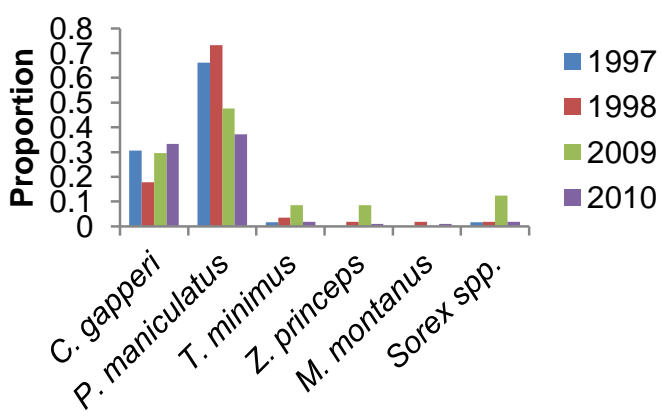

Figure 3. Proportion of individuals per species for 1997, 1998, 2009 and 2010 for the east facing burn. 


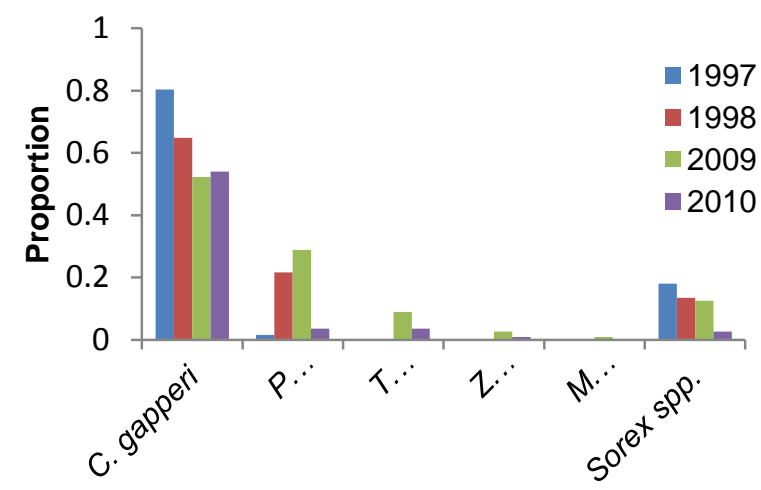

Figure 4. Proportion of individuals per species for 1997, 1998, 2009 and 2010 for the east facing control.

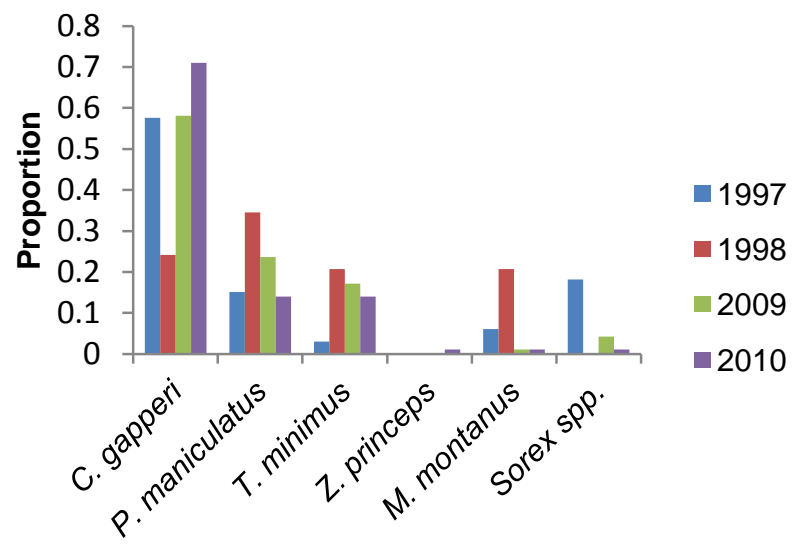

Figure 5. Proportion of individuals per species for 1997, 1998, 2009 and 2010 for the west facing burn.

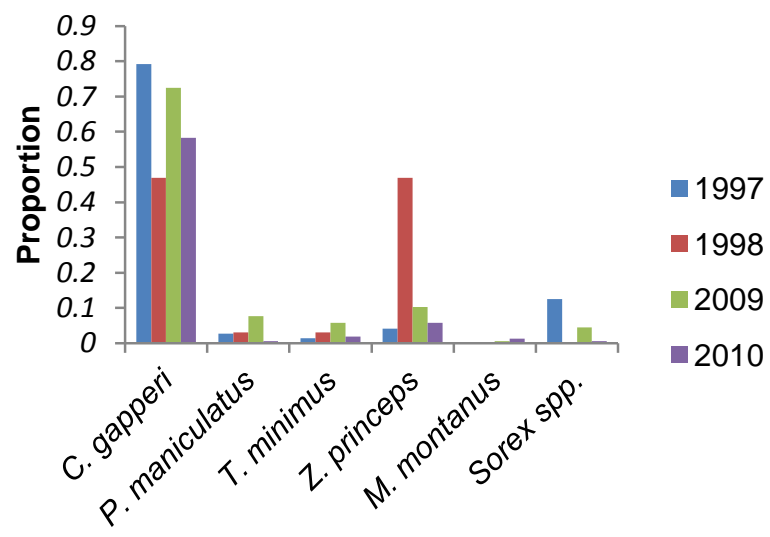

Figure 6. Proportion of individuals per species for 1997 , 1998, 2009 and 2010 for the west facing control.

\section{Microhabitat features}

In some cases there is little if any detectable difference between burned and control grids with respect to various types of cover. Figure 10 illustrates a decrease in log cover since 1997 and similar results were also seen for woody cover.
However, there are more pronounced changes for herbaceous and grass cover (Figure 11 and 12 respectively). For all grids we see a similar trend: an increase in cover. However herbaceous cover is higher in the control grids and grass cover is higher in the burn grids. The amount of bare ground has remained fairly constant for the control grids and has decreased for the burned grids (Figure 13). Unfortunately, we do not have cover class prior to 1997 for any cover class variable.

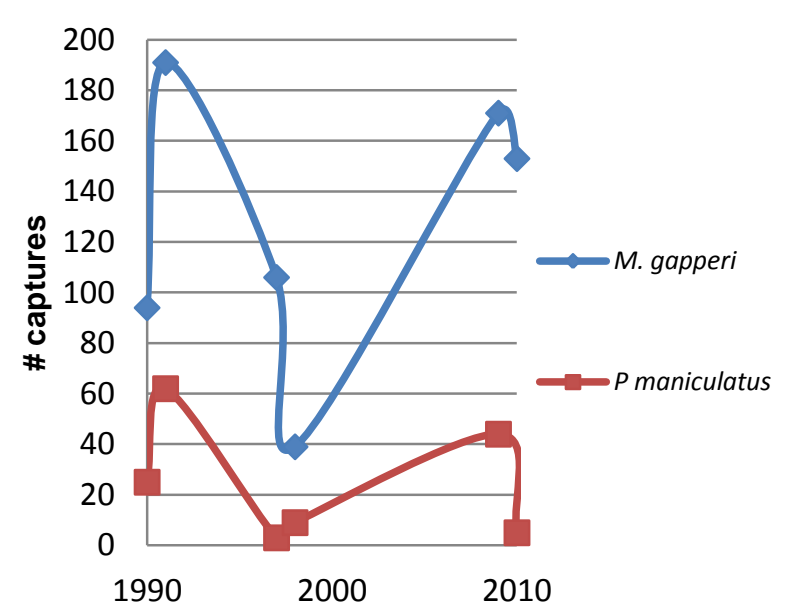

Figure 7. Combined captures for $M$. gapperi and $P$. maniculatus for both control grids. Throughout the study, the number of voles has remained consistently higher.

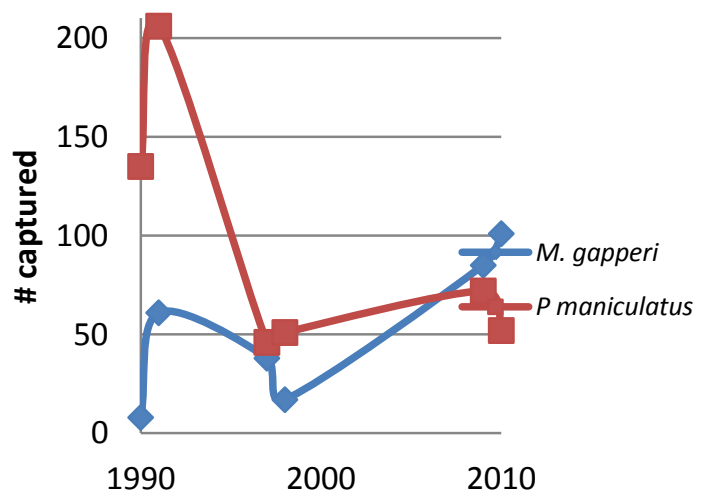

Figure 8. Combined captures for M. gapperi and $P$. maniculatus for both burned grids. Deermice dominated the burn sites immediately after the fire. As time progressed the number of voles increased, eventually overtaking deermice in the number of captures in 2009 and 2010 .

Relationships between small mammals and features of the microhabitat reveal several consistent patterns. Results from a non-parametric KruskalWallis test reveal significant differences $(p<0.05)$ among the species for average diameter of DWD, 


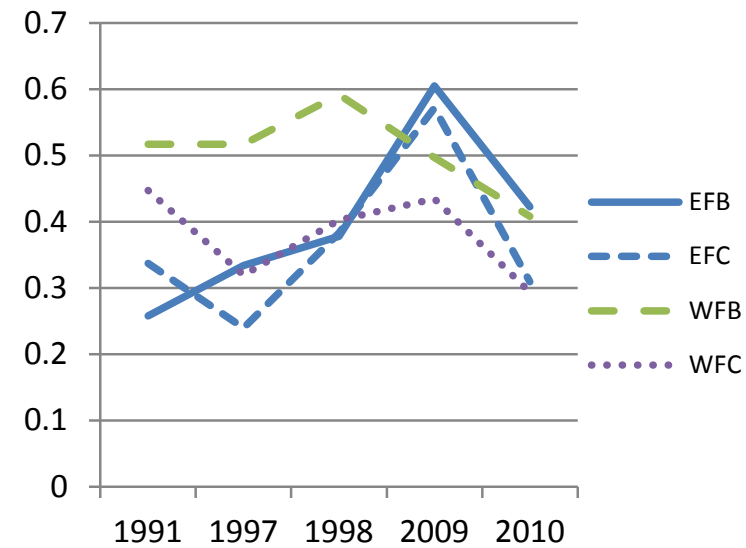

Figure 9. Shannon Diversity Index values for small mammal communities in the four grids for all field seasons. Abbreviations for grids are provided in Table 1.

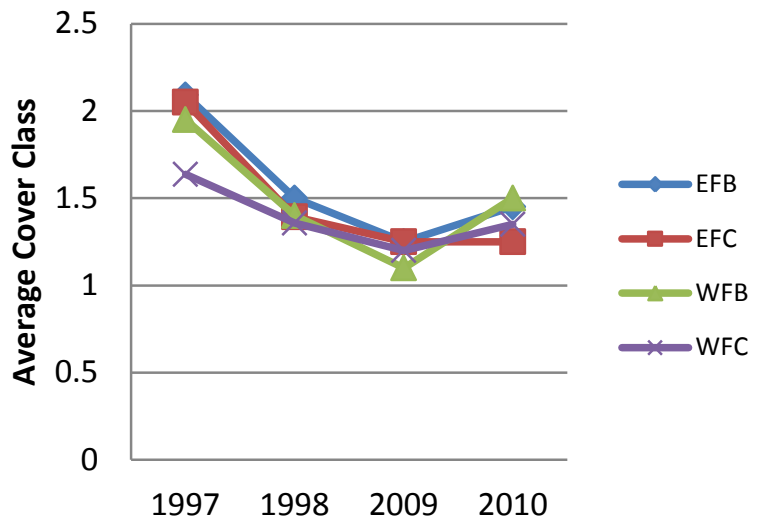

Figure 10. Mean log over class among the four grids from 1997-2010. There is little difference among the four sites, and all show a general decrease in log cover. EFB: East facing burn, EFC: East facing control, WFB: West facing burn, WFC: West facing control. Cover class categories were scored $1-4$, with cover category 1 representing 0 $25 \%$ ground cover, 2 representing $26-50 \%$ cover, 3 representing 51-75\% cover, and 4 representing $76-100 \%$ cover.

average height of DWD, density of DWD (defined as the number of woody debris encountered $/ \mathrm{m}$ ), distance to nearest tree, diameter at breast height for trees, distance to nearest sapling, diameter at breast height for sapling, diameter at breast height for shrubs, and distance to nearest seedling. Only the distance to nearest shrub showed no significant difference among the species.

Capture success of any species was more likely near seedlings $(p=0.026)$, saplings $(p=0.002)$, and trees $(p=0.034)$ but no significant differences were found between capture/non-capture trap locations for other measured variables. This is not surprising since we expected species-specific responses to fire mediated changes in cover and structure. Results of the Kruskal-Wallis Tests for species-specific differences in vegetation parameters however were all significant $(p<0.05)$ with the exception of the mean distance to DWD $(p=0.329)$ and the distance to the nearest shrub $(p=0.285)$. Based on our Tukey tests $Z$. princeps preferred habitats that had significantly less DWD / meter then

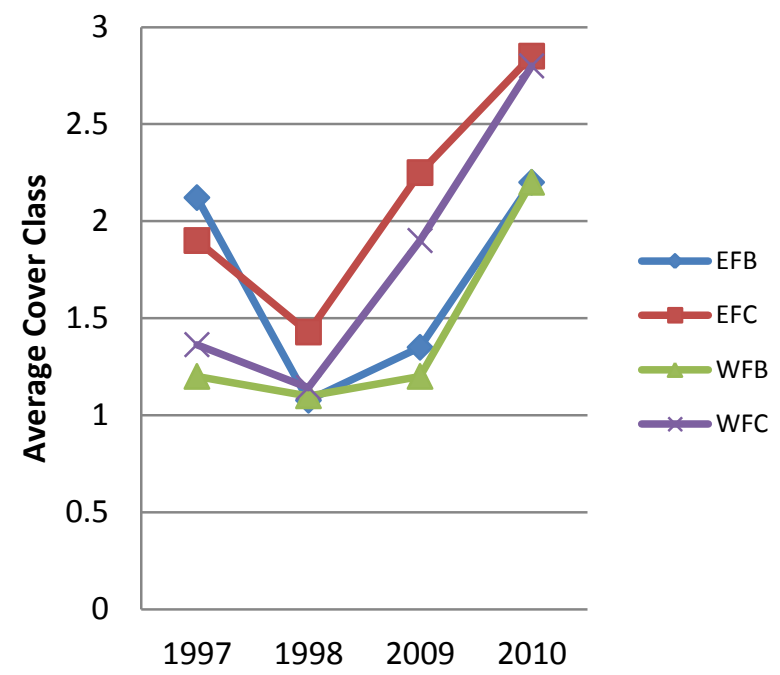

Figure 11. Mean herbaceous cover class among the four grids from 1997-2010. Though similar patterns are seen among the four sites, herbaceous cover is more extensive within the control sites. EFB: East facing burn, EFC: East facing control, WFB: West facing burn, WFC: West facing control. Cover class categories were scored 1-4, with cover category 1 representing $0-25 \%$ ground cover, 2 representing $26-50 \%$ cover, 3 representing $51-75 \%$ cover, and 4 representing $76-100 \%$ cover.

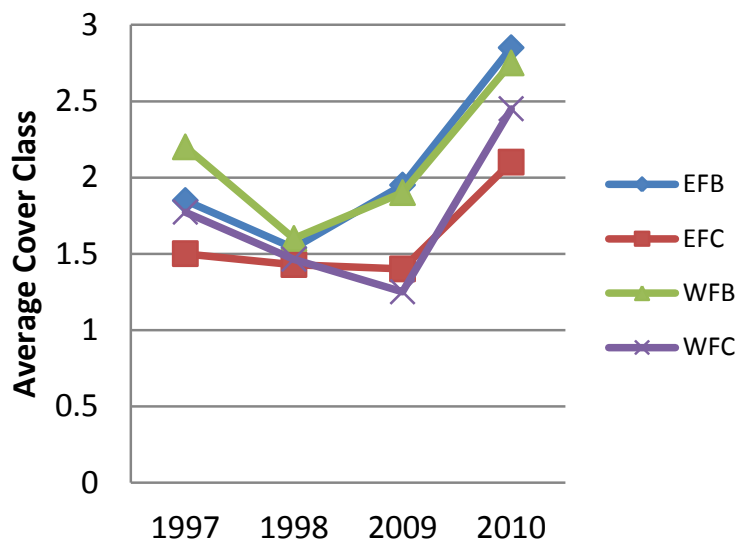

Figure 12. Mean grass cover class among the four grids from 1997-2010. Though similar patterns are seen among the four sites, grass cover is more extensive within the burn sites. EFB: East facing burn, EFC: East facing control, WFB: West facing burn, WFC: West facing control. Cover class categories were scored 1-4, with cover category 1 representing 0-25\% ground cover, 2 representing 26-50\% cover, 3 representing $51-75 \%$ cover, and 4 representing $76-100 \%$ cover. 
areas where no animals were captured and all other species except $T$. minimus. $Z$. princeps also was captured at sites in which trees were closer than sites where no animals or all other species except $C$. gapperi where captured. P. maniculatus preferred habitats with trees of smaller DBH while Sorex preferred habitats with larger DBH trees.

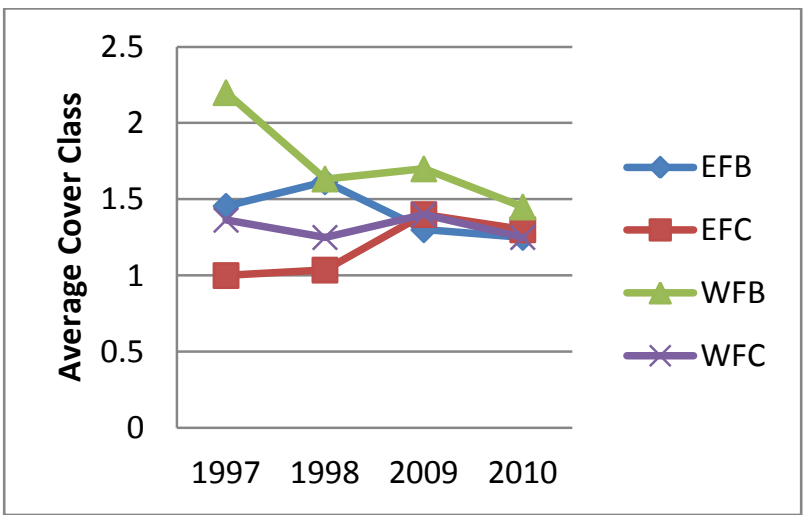

Figure 13. Mean bare ground cover among the four grids from 1997-2010. Bare ground has remained fairly constant in the control grids, but has decreased within the burned sites and by 2010 , they resemble the control sites. EFB: East facing burn, EFC: East facing control, WFB: West facing burn, WFC: West facing control. Cover class categories were scored 1-4, with cover category 1 representing $0-25 \%$ ground cover, 2 representing $26-50 \%$ cover, 3 representing $51-75 \%$ cover, and 4 representing $76-100 \%$ cover.

\section{$\uparrow \quad$ DISCUSSION}

After twenty-two years and several field seasons investigating the structure of small mammal communities following the fires at Huckleberry Mountain, several patterns have emerged. With respect to short-term responses, results from the 1997-98 studies at Huckleberry Mountain are somewhat consistent with other similar studies. The deermouse dominated the east facing burn grid in the years immediately following fire (Figure 3), but not the west facing burn. The red-backed vole was more common in non-burned control sites than the deermouse. However, red back vole numbers did fluctuate, especially in the west facing burn (Figure 5) and in this grid, unlike the east facing burn, the deermouse did not dominate. In the undisturbed sites, numbers of deermice were lower than red-backed voles. The red-backed vole clearly dominated mature unburned habitats. These results are consistent with the summary of results for the vole provided by Fisher and Wilkinson (2005). However, very small sample sizes in 1997-1998 (relative to other investigations) make any final conclusions tentative.

Similar findings have been reported from other investigations conducted in Yellowstone and Grand Teton National Parks. Barmore et al. (1976) trapped small mammals in Grand Teton National Park (GTNP) immediately after the Waterfalls Canyon fire in 1974 and reported that burned sites had higher densities of deermouse and yellow-pine chipmunk (Tamias amoenus) than control grids. Wood (1981) studied two burned (1974 and 1976) and two adjacent unburned spruce/fir/lodgepole forests in YNP in 1978 and 1979 and reported three abundant species: the southern red-backed vole, the deermouse, and the yellow-pine chipmunk. Trap success was higher in unburned forests for the redbacked vole and higher burned sites for the deermouse and yellow-pine chipmunk, although the red-backed vole was the most abundant species in both burned and unburned sites. Finally, Zwolak and Foresman (2007) investigated the response of small mammals for two consecutive years following a forest fire in Montana. They reported an abundance of deermice and reduced numbers of red-backed voles and shrews as compared to unburned sites.

Less is known regarding small mammal responses in the establishment stage (Lee, 2002) 1125 years post fire in boreal forests. The same species are often present, but relative abundances differ. Roy et al. (1995) showed that red-backed voles and masked shrews were common, but still less abundant in burns than old growth stands. Other species such as meadow voles and meadow jumping mice were uncommon or absent in burn sites, presumably due to habitat change and limited food resources. Deermice, though still common, were at a lower relative abundance than earlier years. Results from 2009 and 2010 at Huckleberry Mountain are fairly consistent with findings from these previous studies. The same species are present among the grids 22 years post fire, though proportions within the community are different than in previous years. Red-backed voles are more common in unburned control versus burned grids, though differences between them are less than in previous years. For the east facing grids, proportions of red-backed voles are greater in control versus burned sites, similar to the results of Roy et al. (1995). However, the west facing burn has an unexpectedly high proportion of red-backed voles, similar to the results in 1997. Reasons for such an unusually large number of voles is unclear, but proportions may be misleading, especially from small sample sizes in 1997 (Figure 14). However, estimates of population abundance from 2009-2010 
reveal similar patterns. Initial habitat analyses also do not explain why numbers of voles are so high in the west facing burn. Hopefully, after more extensive analyses of the relationship between small mammal species and habitat, a plausible explanation will emerge.

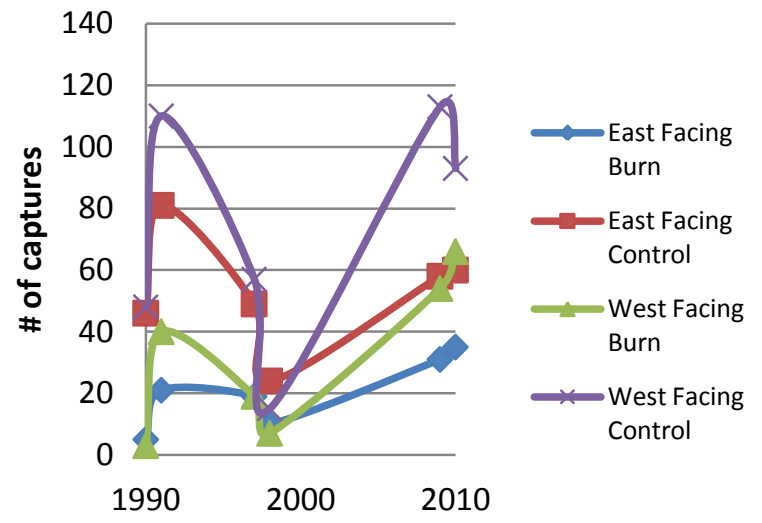

Figure 14. Number of captures of Myodes gapperi among the four sites for all field seasons. Note that few individuals were captured in the late 1990's, and that by 2009 , as many voles were captured in the west facing burn as the east facing control.

Twenty-two years after the Huckleberry mountain fires, community diversity for the two burned sites is decreasing as the habitat recovers and the communities more resemble communities from the unburned control sites. As expected, numbers of deermice were highest in the burned grids immediately following the fires, and over time, their numbers (measured by raw captures as well as abundance estimates) have decreased as numbers of red-backed voles has increased. Despite the numbers of voles and deermice changing over time, diversity indices indicate that the burned and control small mammal communities are still quite different from one another. For the burned grids, the increase in vole numbers and the decrease in the number of deermice are apparently not sufficient to result in any appreciable changes in community structure (as determined by the diversity indices) since the 1988 fires.

The changes in small mammal communities from the initiation to the establishment stages noted above naturally correspond to changes in the structure of the habitat. Fisher and Wilkinson (2005) noted "small mammal abundance increases with stand age after fire, in a manner that corresponds with species-specific habitat association." As expected, deermice numbers are decreasing in burned grids as the habitat recovers and the number of red-backed voles increases (Figure 8). The likely reason for increase in red-backed voles and a decrease in deermice is more favorable micro-environments for the voles, as seen in an increase in cover for herbaceous, grass, and litter (Figs. 11-12). Additionally, in the burned grids, the less common species (e.g., Tamias minimus, Zapus princeps) are becoming more common as habitat recovers (Figure 5).

We continue to analyze the relationship between small mammals and habitat variables. Initial results indicate that habitat features do play a role, but the exact role is still unclear. It will be very interesting to see if any relationships are uncovered.

\section{LITERATURE CITED}

Barmore WJ, Taylor D, Hayden P. 1976. Ecological effects and biotic succession following the 1973 Waterfalls Canyon fire in Grand Teton National Park. Unpublished research project report, Grand Teton National Park, Wyoming. $99 \mathrm{pp}$.

Burt S, Seville RS. 2009. Long-term responses of small mammal communities to the 1988 Yellowstone Fires. UW/ NPS $32^{\text {nd }}$ Annual Report.

Fisher JT, Wilkinson L. 2005. The response of mammals to forest fire and timber harvest in the North American boreal forest. Mammal Review. 35:51-81.

Kirkland G Jr., Parmenter RR. 1997. A five-species assemblage of shrews from the sagebrushsteppe of Wyoming. Journal of Mammalogy. 78:83-89.

Lee P. 2002. Stages of forest succession. In: Song S editor. The Ecological Basis for Stand Management Alberta. Alberta Research Council, Vegreville, Alberta. pp. 3.1-3.3.

Otis DL, Burnham KP, White GC, Anderson DR. 1978. Statistical inference from capture data on closed animal populations. Wildlife Monographs 62:1-135.

Pollock KH, Otto MC. 1983. Robust estimation of population size in closed animal populations from capture-recapture experiments. Biometrics 39:1035-1049. 
Rexstad E, Burnham KP. 1991.User's Guide for Interactive Program CAPTURE. Colorado Cooperative Fish \& Wildlife Research Unit, Colorado State University, Fort Collins, Colorado.

Roy L, Stelfox JD, Nolan JW. 1995. Relationships between mammal biodiversity and stand age and structure in aspen mixedwood forests in Alberta. In: Stelfox JB. Editor Relationships Between Stand Age, Stand Structure, and Biodiversity in Aspen Mixedwood Forests in Alberta. Jointly published by Alberta Environment Center (AECV95-R1), Vegreville, Alberta and Canadian Forest Service (Project No 00014), Edmonton, AB. pp. 159-189.

Seville RS, Spildie D, Stanton NL. 1997. Long-term response of small mammal communities to the 1988 Huckleberry Mountain fire. UW/NPS $21^{\text {st }}$ Annual Report.

Spildie DR. 1994. The density and distribution of small mammals in Grand Teton National Park, Wyoming. Unpublished M.S. Thesis, University of Wyoming. 113 pp.

Stanton NL, Buskirk SW, Spildie DR, Miller SL. 1991. Habitat distributions of small mammal communities in Grand Teton National Park. UW/NPS $15^{\text {th }}$ Annual Report.
Stanton NL, Buskirk SW, Spildie DR, Miller SL. 1992. Habitat distributions of small mammal communities in Grand Teton National Park. UW/NPS $16^{\text {th }}$ Annual Report.

Stanton NL, Spildie DR, Seville RS, Fowler JF, Buskirk SW, Miller SL. 1998. Captures and recaptures of small mammals to assess responses to fire in a coniferous forest in the Greater Yellowstone Area. University of Wyoming/ National Park Service Research Center $22^{\text {nd }}$ and $23^{\text {rd }}$ Annual Reports, pages 71-77.

Taylor DL. 1973. Some ecological implications of forest fire in Yellowstone National Park, Wyoming. Ecology 54:1394-1396.

White GC, Burnham KP, Otis DL, Anderson DR. 1978. User's Manual for Program CAPTURE, Utah State Univ. Press, Logan, Utah.

Wood MA. 1981. Small mammal communities after two recent fires in Yellowstone National Park. Unpublished M.S. Thesis, Montana State University, Bozeman, MT. pp.

Zwolak R, Foresman KR. 2007. Effects of a standreplacing fire on small mammal communities in montane forest. Canadian Journal of Zoology. 85:815-822. 